\title{
Multi-pin modelling of PWR fuel pin ballooning during post-LOCA reflood
}

L Ammirabile1 , S P Walker²

\begin{abstract}
Experiments investigating post-LOCA reflood generally indicate little coherence to fuel pin ballooning, and an absence of significant blockages and un-coolable regions of the core. Computational modelling is unable to predict this; the usual 'representative pin' models neither take into account the heterogeneity of the core, nor incorporate the dynamic coupling between the changing core geometry, and the flow paths taken by the coolant. In this paper we present a composite model, able to treat distinct pins mechanistically, and able to incorporate their (distinct) swelling behaviour into the thermal-hydraulic model of the reflood, allowing the cooling of a pin to be directly affected by the deformation of itself and its neighbours.
\end{abstract}

\section{INTRODUCTION}

In this paper we describe the development and initial application of a new computational model to analyse the ballooning of multiple fuel pins in the re-flood phase of loss of coolant accidents in PWRs. The main objectives of this new model are:

(i) To allow proper incorporation of the many and significant systematic and stochastic differences between pins, and

(ii) To allow the modelling of the coolant flow to take account of the dynamically changing geometry as pins begin to balloon.

Such improved modelling is important to help reduce conservatisms in safety-case development, thereby widening operational envelopes. It will also be necessary when

\footnotetext{
${ }^{1}$ Institute for Energy, Joint Research Centre, Petten 1755 ZG, The Netherlands, Tel.: +31 224 565 064; fax: +31 224565 621, luca.AMMIRABILE@ec.europa.eu

${ }^{2}$ Mechanical Engineering Department, Imperial College, London SW7 2BX UK
} 
page 2 of 30

investigating the implications of, for example, moves to higher burn-up fuel, and advanced high ductility cladding.

In Section 2 we present the background to this issue: the circumstances and consequences of such ballooning, and we describe analysis methods that have been employed to date. The respects in which greater fidelity of modelling is needed are identified, and the objectives of the present model outlined.

The development of the present model is described in Section 3. In Section 4 are presented a series of applications of the model, and discussion and conclusions are presented in Section 5.

\section{BACKGROUND}

Amongst the most severe of postulated accidents in a PWR is the 'double ended guillotine pipe break'. In this, essentially total coolant loss is predicted to occur in of order 100 seconds, leaving the fuel no longer covered by coolant. Although the nuclear chain reaction will be shut down, this uncovered fuel will initially be generating significant thermal power $(\sim 6 \%$ of nominal, of order 200MW) from decay heating.

When the pressure in the core falls to a sufficiently low level, large volume / low pressure coolant injection will be provided by the emergency core cooling system, re-flooding the core from the bottom up, and cooling the fuel.

Until this re-flood water reaches it, fuel cladding will be cooled by only a relatively low flow rate of steam and entrained droplets generated at the re-flood water surface. Fuel and cladding temperatures will rise, and the clad will become susceptible to creep. Zircaloy under these conditions has both a low creep strength and high ductility. With the core being at essentially atmospheric pressure, and with overheated, internally pressurised pins, there is the potential for radial swelling (ballooning) of the cladding. Such ballooning will cause the cladding to approach the cladding of neighbouring pins, which themselves may also be ballooning. The flow area available for cooling vapour, and eventually liquid water coolant, will be reduced. If large numbers of adjacent pins all balloon over similar axial locations, 
there could be sizeable regions of the core to which the re-flood water gains little or no access. Decay heating will continue, and widespread fuel melting and clad failure becomes a possibility.

\subsection{Experimental studies of re-flood and ballooning}

This ballooning phenomenon under re-flood conditions has been investigated in a number of experiments (Donaldson et al. 1985; Gibson et al. 1982; Ihle and Rust 1984; Jowitt et al. 1984; Karwat 1984; Loftus 1982; Pearson et al. 1989). There is not room for a detailed review here, but broad general conclusions are that:

(i) Ballooning is to be expected, and can be pronounced, with ballooning sufficient to reach neighbouring pins readily occurring.

(ii) The ballooning observed experimentally is quite non-uniform, and large coherent blockages are not seen.

\subsection{Modelling of the ballooning process}

There is a large number of fuel pin modelling codes that have addressed the ballooning issue. Principal amongst these are the two Westinghouse codes BART and TAPSWEL, used for analysis of the UK Sizewell plant (Healey and Board 1982), the KFK code SSYT code (Borgwaldt and Gulden 1982) and the UKAEA-developed MABEL code (Bowring 1982a). The FRETA-B code (Uchida, M., Nakamura, J. et al.; 1982) is notable for present purposes in that it is an extension of FRETA to analyse multiple pins.

All such analyses require some estimate of the thermal-hydraulic conditions to which the pin is subject, and the detail and fidelity with which this is done differs between codes.

Existing codes generally base their results on analysis of a single 'representative' pin. If it does predict ballooning, such a model will necessarily predict uniform, coherent ballooning for all the pins it represents. This will be associated with impeded cooling of a large region of the core, impairing the quenching of the core by re-flooding and leading to overheating and failure of fuel rods. 
These predictions, though, are in contrast with the experimental results of several multi-rod tests (Gibson et al. 1982) (Karwat 1984) (Chapman 1978). Particularly in the MT-3 test, a wide distribution among the rods of burst strain was observed. Whilst the axial burst locations were concentrated over two grid-spans, and near to the grids, their axial distribution was sufficiently wide to prevent uniform coherent ballooning. The maximum channel blockage formed at any elevation was significantly lower than the predictions of the single-pin code BART (Healey and Board 1982).

It is this mis-match between experimental observations and modelling predictions that provides the motivation for the present work.

\subsection{Non-uniformities and blockage formation}

Any modelling of the behaviour of a group of pins via analysis of a single representative pin will necessarily predict uniform behaviour of all members of the group. In the present context, if a single representative pin is predicted to balloon, there is an associated prediction that simultaneous coplanar ballooning by all the pins so represented will occur. These will then form a blockage over the whole region represented. As we have seen, this is happily not observed in experiments. We will now consider some of the reasons why this may be the case. Firstly, ballooning is a creep phenomenon. The creep rate of Zircaloy is highly sensitive to temperature, with the deformation rate approximately doubling for every $20 \mathrm{~K}$ rise in temperature (Donaldson et al. 1985). It is also highly sensitive to stress, being proportional to stress to the power of about 5 in the alpha phase. For both of these reasons, the rate of creep, and the extent of ballooning, are highly sensitive to small pressure and temperature differences between individual pins (and, indeed, around the azimuth of a single pin).

Pins will differ from each other both systematically and stochastically in a variety of ways. Spatially, flux and power both will exhibit a general radial reduction over the whole core. Overlaid on this are more local variations, occasioned by, for example, proximity to control rods, or by the slightly larger inter-pin gaps between adjacent fuel assemblies. These power variations will affect clad temperature, and pin internal temperature and burnup, both of 
which will affect pin internal pressure. Likewise, local variations in coolant flow patterns can affect clad temperature. Manufacturing tolerances, for example in dimensions, or in fill gas pressure, will cause essentially random variations between pins.

During ballooning the relative movement of the cladding and the fuel pellet stack is also important; in general the fuel - cladding gap (or intimacy of contact) will not be uniform all around the perimeter of the pin. This eccentricity will cause azimuthal variations in cladding temperature that, coupled to the strong temperature dependence of creep rate, exert a strong influence on ballooning and clad creep rupture. The direction of eccentricity (the direction in which pellet and clad are in closest contact) is likely to determine the azimuthal location of highest clad temperature, and consequently the location of eventual cladding failure.

The degree of eccentricity will largely determine the degree of azimuthal temperature variation. This has a major influence on the local creep rate, and consequently on the average circumferential strain at which clad failure occurs. This whole issue of pellet eccentricity is both important and difficult. Eccentricity is essentially random; neither its direction, nor its magnitude can be predicted, and it is very difficult even to measure. However, it plays this major role in determining pin failure.

\subsection{The interaction of pin mechanical response and thermal hydraulics}

Given the non-uniform ballooning behaviour actually observed, the interaction of this with the thermal hydraulic behaviour of the core becomes important. There will tend to be a diversion of flow from coolant passages constricted by blockages to neighbouring, unconstricted ones. The degrees to which vapour flow and droplet flow are diverted are, though, likely to be different. The result is that coolant temperatures, flow rates and heat transfer coefficients are likely to be caused to differ between coolant passages, and to differ around the perimeter of individual pins. In particular, the flow diversion associated with ballooning of one pin might inhibit ballooning of its neighbours, by diverting more coolant flow to them. If this could indeed be convincingly demonstrated it would provide valuable evidence relating to the likelihood of gross blockage formation. 


\subsection{The objectives of the present work}

As discussed above, it is to be expected that differences between individual pins, both systematic and random, will cause significant differences in their ballooning behaviour. Some will balloon more than others, some earlier or later than others, or at different axial locations, and the average circumferential strain at which clad failure will occur will differ. (Clad rupture is particularly important, as once it occurs further ballooning will not happen, and that pin will not contribute further to blocking coolant flow.)

The objectives of this present work can be summarised as twofold:

(i) To develop a computational model capable of representing the effects of inter-pin inhomogeneity, by the mechanistic analysis of multiple individual pins.

(ii) To develop a best-estimate thermal-hydraulics model of the re-flood process, that dynamically takes into account the changing core geometry as each of these individual pins does or does not balloon.

It may be the case that together these phenomena cause ballooning not to be coherent. In the absence of large numbers of contiguous pins with coplanar balloons, there will remain scope for the re-flood water to have good access to all pins. If it is so, it may be that design constraints and operating rules implemented because of fears of generating large un-coolable regions may be able to be relaxed. These issues are important for presently operating plants, and will become increasingly so for more advanced, higher burnup systems.

\section{THE MULTI-PIN MODEL}

\subsection{The requirements for the model}

There are two main interlinked requirements of any model that incorporates this inhomogeneity and coupled deformation - thermal hydraulics:

(i) The thermal-hydraulic analysis of the re-flood process must be able to be influenced by the changes in the geometry of the coolant passages as individual pins balloon, and flow paths and flow speeds are modified by this. 
(ii) A thermal - mechanical model of the behaviour of each of many pins must be provided, able to incorporate the many and various differences between individual pins discussed above. These models must be able to accept dynamically-changing information from the thermal hydraulics model, and use it in computing the mechanical response of each pin. Any changes in pin (and hence in coolant flow passage) geometry must then be conveyed to the thermal-hydraulic model.

Both the thermal-hydraulic model and the thermal-mechanical pin model are obviously complex in their own right. Development of a single composite code is both impractical, and un-necessary. The approach adopted was to use extant codes for each, and to couple them dynamically, allowing (for example) modified geometric information computed by the mechanical models to be provided regularly to the thermal hydraulic code. This is used to compute the changed flow patterns and consequent thermal conditions to which each of many pins modelled by the mechanical models was subject, and this information transmitted to these mechanical models.

\section{$3.2 \quad$ The codes employed}

There are various candidate codes for each of the thermal hydraulic and thermal mechanical models. Selection was influenced by their technical suitability, availability of source code, and by licensing issues. The pair selected was RELAP for the thermal hydraulics, and MABEL to perform the thermal-mechanical analysis of the pin. Each of these is discussed further below, followed by a discussion of the TALINK code used to manage the dynamic data transfer between them. The composite, three-code model will be termed MATARE (MAbel, TAlink, RElap).

\subsubsection{RELAP}

The RELAP code (Ransom 1997a) was developed for best-estimate transient simulation of light water reactor coolant systems during postulated accidents. The code was developed at Idaho National Engineering Laboratory (INEL) for the Nuclear Regulatory Commission (NRC). Code applications include analysis to support rule-making, licensing audit calculations, 
evaluation of accident mitigation strategies, evaluation of operator guidelines, and experiment planning and analysis.

The code is based on a non-homogeneous and non-equilibrium model for the two-phase system that is solved by a fast partially implicit numerical scheme. The RELAP analysis is not a full 'CFD' treatment. Rather, the code is one-dimensional and solves six basic field equations for six independent variables: pressure, specific internal energies for liquid and vapour, void fraction and liquid and vapour velocities. The constitutive relations include models for defining flow-regimes and flow-regime-related models for inter-phase drag and shear, the coefficient of virtual mass, wall friction, wall heat transfer, and inter-phase heat and mass transfer.

A boiling curve is used in RELAP to govern the selection of the wall to fluid heat transfer correlations. The code boiling curve logic is based on the value of the heat slab surface temperature. These correlations are based on fully developed steady-state flow, while entrance effects are considered only for the calculation of the critical heat flux.

In the quench front model, the code uses a fine mesh model that inserts additional nodes into the heated wall if significant axial temperature gradients exist along the wall. This allows a more accurate representation of the true localised energy release from a localised portion of a heater or nuclear rod rather than the energy release from all the structures within the fluid node. Fine mesh heat transfer cells for axial and radial conduction are superimposed on the coarser hydraulic computational cells usually used for the heat transfer analysis.

No specific models are used to simulate the spacer grids in the hot rod bundle. In particular, there are not specific models to include the effect of heat transfer enhancement induced by the grid.

Entrainment and de-entrainment is only calculated for annular-mist or horizontal stratified flows. 


\subsubsection{MABEL}

The MABEL code (Bowring 1982a), developed by the UKAEA, carries out a radial and azimuthal $(R-\theta)$ solution of the temperature and strain field, in a single pin, at all axial nodes. The behaviour of surrounding rods is taken into account to some degree by the use of input parameters that determine the extent to which the behaviour of the other rods reflects that of the rod analysed.

The MABEL thermal-hydraulic routine is capable of modelling the flow in four sub-channels surrounding the pin of interest. Some account is taken of flow diversion due to ballooning or bowing. The MABEL model, however, assumes a homogeneous, quasi-steady two-phase flow, so it is normally used to perturb input thermo-hydraulic conditions obtained from bestestimate codes such as RELAP5 or TRAC.

The pellet stack is assumed to remain intact and the eccentricity of the pellets relative to the cladding, both direction and magnitude, is prescribed by the user.

\subsubsection{TALINK}

Both of MABEL and RELAP need to run simultaneously, and to pass information from one to the other as the computation progresses.

The code TALINK (Transient Analysis code LINKage) (Page 1999) is a proprietary utility code, designed to control the data transfers required for the execution of a set of coupled transient analysis codes performing their calculations in separate operating system processes. The data transfers are linked on many-to-one and one-to-many bases with the TALINK code being the central component in this structure and the other codes being regarded as client codes. As required, TALINK will perform simple computations on the data transferred; for example, converting values from one set of units to another. Fig. 1 shows schematically the interactions between the codes. 


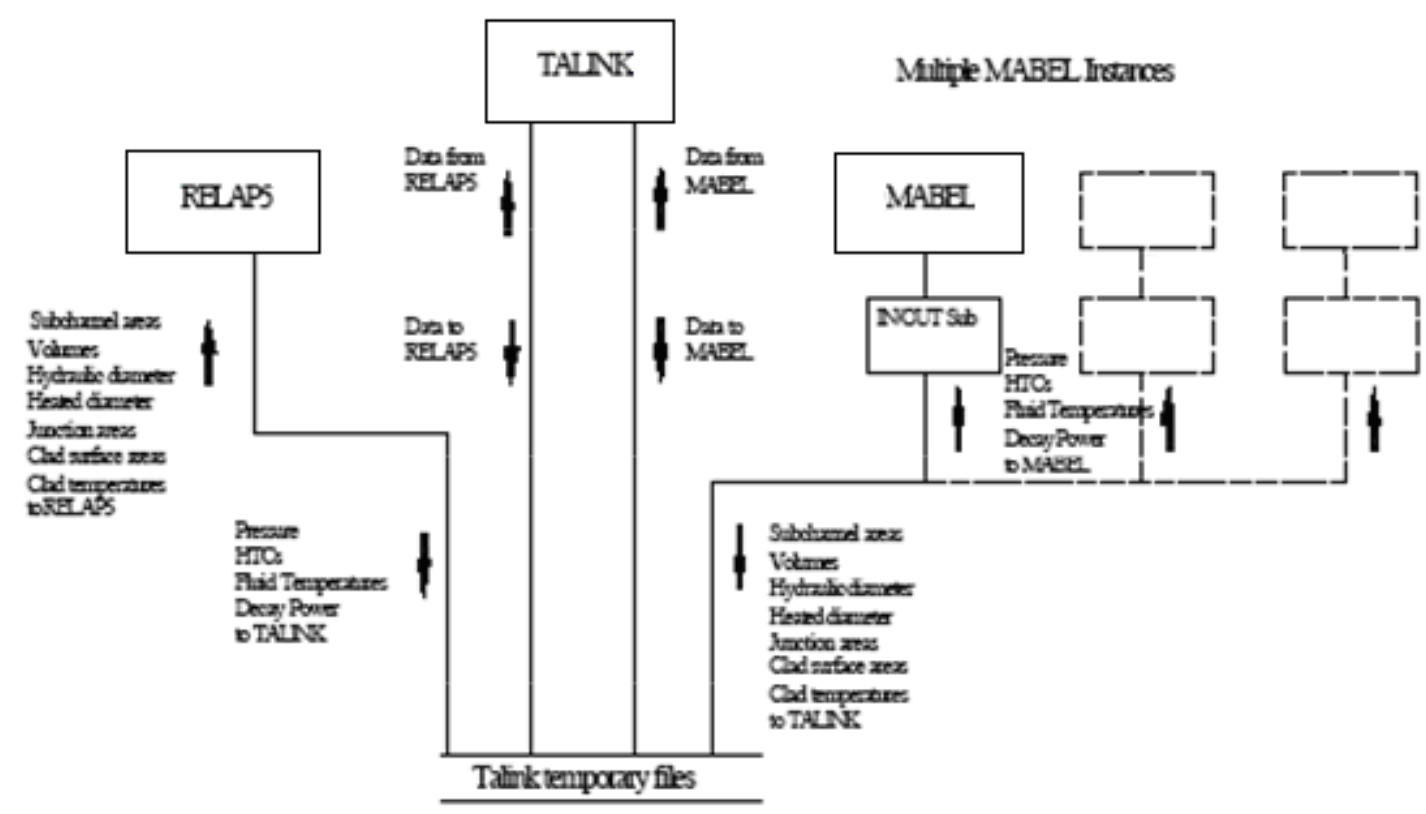

Fig. 1. The interactions and relationship between RELAP, MABEL and TALINK.

\subsection{The MATARE model; issues arising in coupling the models}

Our eventual objective is to model a significant part of a core; more than a handful of pins, but probably not dozens, due to computational resources needed. Each coolant channel within this region is modelled by RELAP, with appropriate coupling between channels to allow crossflow and so on. Each pin in this collection will be modelled by an individual instance of the MABEL code.

Fig. 2 shows in cross-section a typical region of the core being analysed.

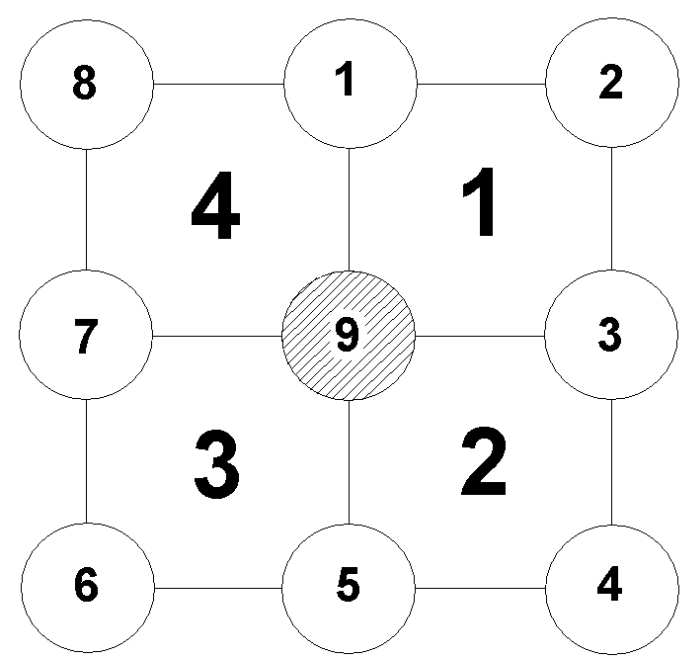

Fig. 2. Plan view of a typical region of the core to be analysed, showing pins and coolant subchannels 
The numbered coolant passages are together modelled in a multi-channel model in RELAP. Crossflow between adjacent RELAP channels is permitted by the use of RELAP's 'cross flow junctions', located at mid-height of each axial node. The rate of cross flow is computed as a function of the transverse pressure difference between channels at this axial location. The use of cross-flow junctions however is only an approximation to a multidimensional system. The transverse convection of axial momentum is assumed zero (as would occur in a manifold). This is not generally true in a rod-bundle geometry, where the transverse flow usually retains its axial momentum. However, this can be tolerated if transverse momentum fluxes are not too large. The fineness of axial discretisation varies greatly along each channel; much finer meshing is required in regions where peak cladding temperatures are reached, and ballooning is expected.

Each pin is modelled by an individual instance of the MABEL code. Each pin is seen to be cooled by the flow in four surrounding RELAP channels, and the thermal-hydraulic conditions computed in each of these four channels are transmitted to the MABEL model via TALINK. The principal data conveyed from RELAP are:

-Pressure;

-Heat transfer coefficient to the gas;

-Heat transfer coefficient to the liquid;

-Gas temperature;

-Liquid temperature;

-Decay power.

Various manipulations of these data are required to provide the information MABEL needs. In particular, MABEL treats only a single-phase coolant, so RELAP's distinct gas and liquid temperatures and heat transfer coefficients are combined into an effective 'heat flux' boundary condition for use in MABEL. 
The MABEL model is based on a finite difference solution of the equations describing temperature and strain variation in the cladding-gap-pellet combination comprising the pin. The RELAP model provides four distinct sets of conditions around the azimuth of the pin. These are provided to MABEL, and feed into MABEL's analysis of azimuthal variation of thermal and mechanical behaviour.

The principal data returned by MABEL to RELAP are the geometry associated with the pin (flow areas, surface areas, etc) and the azimuthal variation of cladding surface temperature.

It is worth noting that the heat structures (Ransom 1997a) used in RELAP to simulate the fuel rods have a fixed geometry, so that the cladding temperature profiles calculated in each of RELAP and MABEL are different when approaching the ballooning region. This could lead to computation of an inconsistent amount of energy released to the fluid during ballooning. Since the thermal model in MABEL is based on the presently-computed geometry (i.e. including ballooning), MABEL's temperature calculation is likely to be more accurate than that of RELAP. Hence, the cladding temperature profile is calculated in MABEL and its values sent to RELAP, which uses them to compute the energy released to the fluid.

\begin{tabular}{|l|l|l|}
\hline RELAP to MABEL & MABEL to RELAP & MABEL to MABEL \\
\hline Pressure & Sub-channel areas & Pin diameters \\
\hline HTCs (gas, liquid) & Volumes & Pin positions \\
\hline Fluid temp (gas, liquid) & Hydraulic diameter & Pin temperatures \\
\hline Decay power & Heated diameter & \\
\hline & Junction areas & \\
\hline & Clad surface areas & \\
\hline & Clad temperatures & \\
\hline
\end{tabular}

Table 1. Variables exchanged between RELAP and MABEL instances

In its computations of conditions in a pin, MABEL takes some account of the behaviour of neighbouring pins. This is generally done in MABEL by the incorporation of a 'notional neighbour'. In the present work, where distinct inter-pin interactions lie at the core of our interest, it is necessary to adopt a more accurate approach. Details of the conditions in 
neighbouring pins, each individually the subject of a distinct MABEL computation, are broadcast to affected pins via the TALINK mechanism.

Table 1 above summarises the data exchanges between the various models.

\subsection{Incorporation of a model of the fuel pin spacer grid}

Fuel spacer grids have a marked effect, both thermal and mechanical, on fuel behaviour during the period prior to re-flood, whilst the quench front is yet to reach the point in question.

\subsubsection{Mechanical effects of grids}

PWR fuel has inconel spacer grids to hold the fuel pins in their correct lateral positions, with typically eight of these grids being located about 500mm apart axially.

Ballooning is most likely to occur between the fourth and fifth and fifth and sixth grids in a typical PWR 8-grid assembly, as this is where the peak cladding temperature is likely to be located(Gibson et al. 1982).

The grids act as a mechanical restraint on ballooning of the clad, with an abrupt termination of ballooning observed just upstream of the grid, and a more gradual reversion to full ballooning occurring downstream of the grid (the classic 'carrot shape').

\subsubsection{Thermal effects of grids}

The grids affect heat transfer in a number of ways.

Heat transfer enhancement by induced turbulence: The finite thickness of the spacer causes a flow obstruction in the channel, so that the flow contracts and then expands downstream of each grid. This, and wall shear stress on the grid, disrupt the flow, and thereby disrupt the fluid and thermal boundary layers on the pin. This increases the local heat transfer within and downstream of the grid. Different single-phase experiments (Pearson et al. 1989) showed that the heat transfer downstream of a spacer grid can be modelled as an entrance effect phenomenon, in which the abrupt contraction and expansion result in establishment of a new 
boundary layer downstream of the grid. This entrance effect on the heat transfer decays exponentially downstream of the grid(Yao et al. 1982).

Steam cooling through grid wetting: Since the grid is unheated and has a large surface area, the impinging droplets can generally re-wet it much earlier than they can wet the fuel rods at the same elevation. Once the grid is re-wetted it cools the super-heated steam passing through it so that the steam temperature above the grid is much lower than below it. This significant steam de-superheating improves the heat transfer from rod to steam downstream of the grid (Pearson and Denham 1989).

Radiant heat sink: As discussed before, the grid is very likely to be wetted due to the droplet cooling and its temperature kept close to the saturation temperature of the fluid by continuous droplet impingement. In these conditions, the spacer can become a heat sink for thermal radiation from the rod bundle, whose temperature can be hundreds of degrees higher than fluid saturation temperature (Yao et al. 1982).

Heat transfer enhancement by droplet breaking-up at a grid: The presence of the grids in the flow channel may cause some droplets to impact and break-up into smaller droplets. The increase in the total droplet surface area may enhance the inter-phase heat transfer and reduce the steam temperature. Smaller droplets may also re-wet the grid itself more easily (Adams and Clare 1982).

\subsubsection{Incorporation of grid effects into the model}

The multi-pin code MATARE has been constructed to simulate the first four of the above grideffects. The fifth, droplet break-up, is considered to be of less significance, particularly in the case of wet grids(Adams and Clare 1982). The models adopted, and their implementation, are described below.

Model for mechanical restraint:

In the MABEL code it is possible to define a strain limit for rod deformation over an axial interval. This strain limit is set to a small value for an axial location coincident with a grid 
spacer, to represent the amount by which the rod can deform until it is restrained by the grid. For a non-grid interval, no strain limit is imposed(Bowring 1982b).

Model for heat transfer enhancement by induced turbulence:

The approach adopted was based on experimental measurements of heat transfer downstream of grids. The correlation for the heat transfer enhancement used in MATARE was developed by Yao, Hochreiter and Leech(Yao et al. 1982):

$F_{g}=\frac{N u_{\chi}}{N u_{o}}=1+5.55 a_{r}^{2} e^{\left(\frac{-0.13 \chi}{D_{h}}\right)}$

for $\operatorname{Re}>104$ and $0.256<\mathrm{a}_{\mathrm{r}}<0.35$

where:

$\mathrm{Nu}_{\chi}$ and $\mathrm{Nu}_{0}$ are Nusselt numbers at the wall with and without the grid spacer,

$a_{r}$ is the fraction of the sub-channel blocked by the grid,

$\chi$ is the distance downstream from the grid trailing edge.

$\mathrm{D}_{\mathrm{h}}$ is the hydraulic diameter at the grid location.

The heat transfer coefficient multiplied by this factor gives the enhanced heat transfer coefficient at the wall in the presence of the grid.

The model has been implemented in the MABEL code, where the enhancement factor is calculated and multiplied by the heat transfer coefficient computed from RELAP data.

Model for the grid heat structure:

In RELAP it is possible to define a structure component ('heat structure') that can simulate the grid and its interaction with the fluid mixture. The grid heat structure is modelled by a slab of surface area equal to the grid surface area in the channel. In order to achieve the correct pressure drop at each grid spacer junction, a loss coefficient is input at each grid location (Ransom 1997b). 


\subsection{Pellet eccentricity}

During the course of a LOCA, and in particular under ballooning conditions $s_{L}$ it is quite probable that fuel pellets will move to be no longer totally concentric with the adjacent cladding. There is firm evidence for this, from, for example, the MT tests (Donaldson et al. 1983) where the wide burst strain range was caused by azimuthal temperature gradients induced by pellet eccentricities.

Indeed, it is probable that the degree of eccentricity will be a major determinant of the timing of clad failure, as the highly non-linear cladding creep behaviour makes it very sensitive to the azimuthal temperature variations that eccentricity induces; this was alluded to earlier. The direction of this eccentricity, and probably its degree, will be essentially random, and this

Given the highly stochastic character of this phenomenon, the MABEL model(s) employed are able to accommodate the specification of arbitrary initial eccentricity.

\section{APPLICATION OF THE MATARE MODEL}

In this section we report a series of applications of the coupled MATARE model. The main aim of these is to begin to address the questions:

-do individual pins behave differently from each other as a result of plausible systematic and stochastic differences between them?

-does the deformation behaviour of one pin influence thermal hydraulic conditions sufficiently to modify the deformation behaviour of its neighbours?

Along with addressing these, the applications will examine the stability of the coupled model, the ability of each of the model's components to use information computed by the other, and to make information available for use by the other, and the ability to model phenomena such as the influence of grids.

The applications fall into three groups:

(a) Single pin tests 
(b) Two pin tests

(c) Two pin tests with grids

They all simulate typical PWR fuel rod channels under re-flood conditions. The basic data for all tests, unless noted otherwise, are in Table 2.

In the first group, single pin tests, RELAP5 pipe components, connected with cross-flow junctions, simulate the four sub-channels. Branch components are used for the lower and upper plenum, while time-dependent volumes and junction components define the re-flood mass flow rate, and control the overall system pressure.

\begin{tabular}{|l|l|}
\hline Pellet diameter & $8.2 \mathrm{~mm}$ \\
\hline Internal cladding diameter & $8.4 \mathrm{~mm}$ \\
\hline External cladding diameter & $9.5 \mathrm{~mm}$ \\
\hline Active fuel length & $3657 \mathrm{~mm}$ \\
\hline Pitch & $12.6 \mathrm{~mm}$ \\
\hline Decay power & $\begin{array}{l}70 \% \text { peak rod power with ANS(79) shaped in a cosine } \\
\text { profile }\end{array}$ \\
\hline Overall system pressure & $0.2 \mathrm{MPa}$ \\
\hline Flooding rate & $0.02 \mathrm{~m} / \mathrm{s}$ \\
\hline Pellet eccentricity & 0.0 \\
\hline Pin fill pressure & $4.5 \mathrm{MPa}$ \\
\hline
\end{tabular}

Table 2. Basic data for all tests, unless specified otherwise.

In the second group, the code simulates the two-pin channels using six sub-channels, with the central double-sized ones in common between the pins.

Each sub-channel is divided into 42 axial nodes whose length varies from 50 to $200 \mathrm{~mm}$. Cross flow between channels is permitted via cross flow junctions.

The fuel rods are simulated by MABEL instances using axial discretisation identical to the RELAP model.

An adiabatic heat-up phase precedes the start of re-flood and provides the initial temperature profile of the fuel rod. 


\begin{tabular}{|c|c|c|}
\hline Model & Test & Definition \\
\hline & SP1 & $\begin{array}{l}\text { One-way linkage: RELAP provides thermofluids } \\
\text { information to MABEL, but RELAP's geometry remains } \\
\text { unaltered }\end{array}$ \\
\hline & SP2 & $\begin{array}{l}\text { Both-way linkage: RELAP provides thermofluids } \\
\text { information to MABEL, and RELAP's geometry is altered to } \\
\text { follow the pin deformation computed by MABEL }\end{array}$ \\
\hline & TP1 & Both-way linkage. Both pins have fill pressure of $4.5 \mathrm{MPa}$ \\
\hline & TP2 & $\begin{array}{l}\text { Both-way linkage. Both pins have fill pressure of } 4.07 \\
\mathrm{MPa}\end{array}$ \\
\hline & TP3 & $\begin{array}{l}\text { Both-way linkage. Pin } 1 \text { has a fill pressure of } 4.5 \mathrm{MPa} \text {; Pin } \\
2 \text { has a fill pressure of } 4.07 \mathrm{MPa} \text {. }\end{array}$ \\
\hline & TPG1 & $\begin{array}{l}\text { Both-way linkage, grid model implemented. Both pins } \\
\text { have fill pressure of } 4.5 \mathrm{MPa} \text {. }\end{array}$ \\
\hline & TPG2 & $\begin{array}{l}\text { Both-way linkage, grid model implemented. Pin } 1 \text { has a } \\
\text { fill pressure of } 4.5 \mathrm{MPa} \text {; Pin } 2 \text { has a fill pressure of } 4.07 \\
\mathrm{MPa} \text {. }\end{array}$ \\
\hline
\end{tabular}

Table 3. Summary test definitions

Clad rupture was inhibited in all tests, as our objective, at this stage, was the analysis of the progression of clad deformation.

\section{1 $\quad$ Single pin tests}

The aim here is to demonstrate proper information transfer and coupling between the RELAP and MABEL analyses.

In Test SP1, RELAP computes fluid temperatures and heat transfer coefficients, and these are passed to MABEL and determine the cooling experienced by the pin. In the upper curve of Fig. 3 we see the final ballooned shape of the pin. With no deformation feedback, and with the clad rupture criterion inhibited, we see substantial ballooning (actually to a radius beyond that which would have made contact with a neighbouring pin), as the cooling provided by 
the vapour and droplet flow is unable to keep temperatures below those at which ballooning occurs readily.

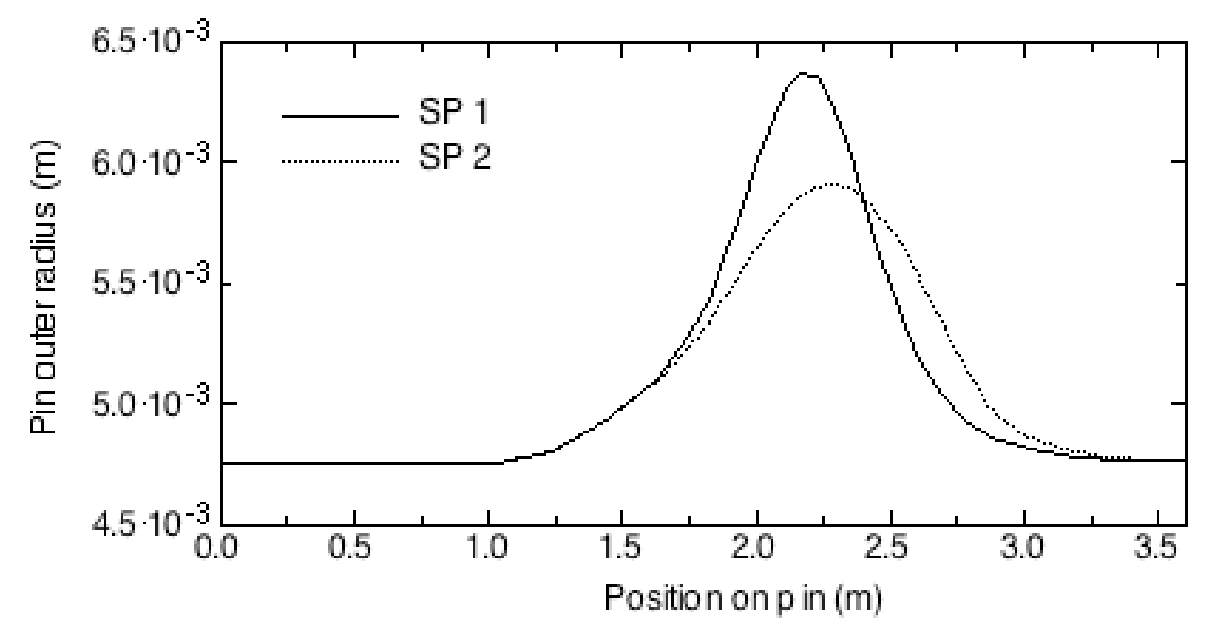

Fig. 3. Pin outer radius at the end of the simulation for each of tests SP1 (solid line, no swelling feedback) and SP2 (dashed, with feedback)

Test SP2 differs in allowing the ballooning computed by MABEL to be fed back to RELAP, modifying the flow area available for the coolant. In this test, with an essentially fixed mass flow rate of coolant, and a non-deforming outer boundary with no opportunity for crossflow, coolant flow speeds are increased as the flow area available reduces. This has the effect of increasing heat transfer coefficients, and is to be expected to reduce ballooning.

The lower curve in Fig. 3 shows the results for SP2, and this is indeed observed; the peak radius reached is lower. At this radius the ballooning has reduced the flow area available significantly, and the consequently higher flow speeds keep the clad cooler.

The full linkage affects not only the magnitude of the ballooning, but also the axial distribution of the strain. An increase in strain rate is associated with the decrease in cooling as the steam-droplet mixture increases in temperature as it moves upwards. Because of the different cooling conditions, Test SP1 shows a more peaked rod shape and a maximum strain position $100 \mathrm{~mm}$ below that of Test SP2.

In Fig. 4 we show the course of test SP2, indicated via the axial cladding temperature profile plotted at a series of times. The initial heat-up phase, lasting till rather more than 50 s, is clear. We then see the gradual rise of the quench front, with temperatures being sharply reduced as the liquid level increases. 


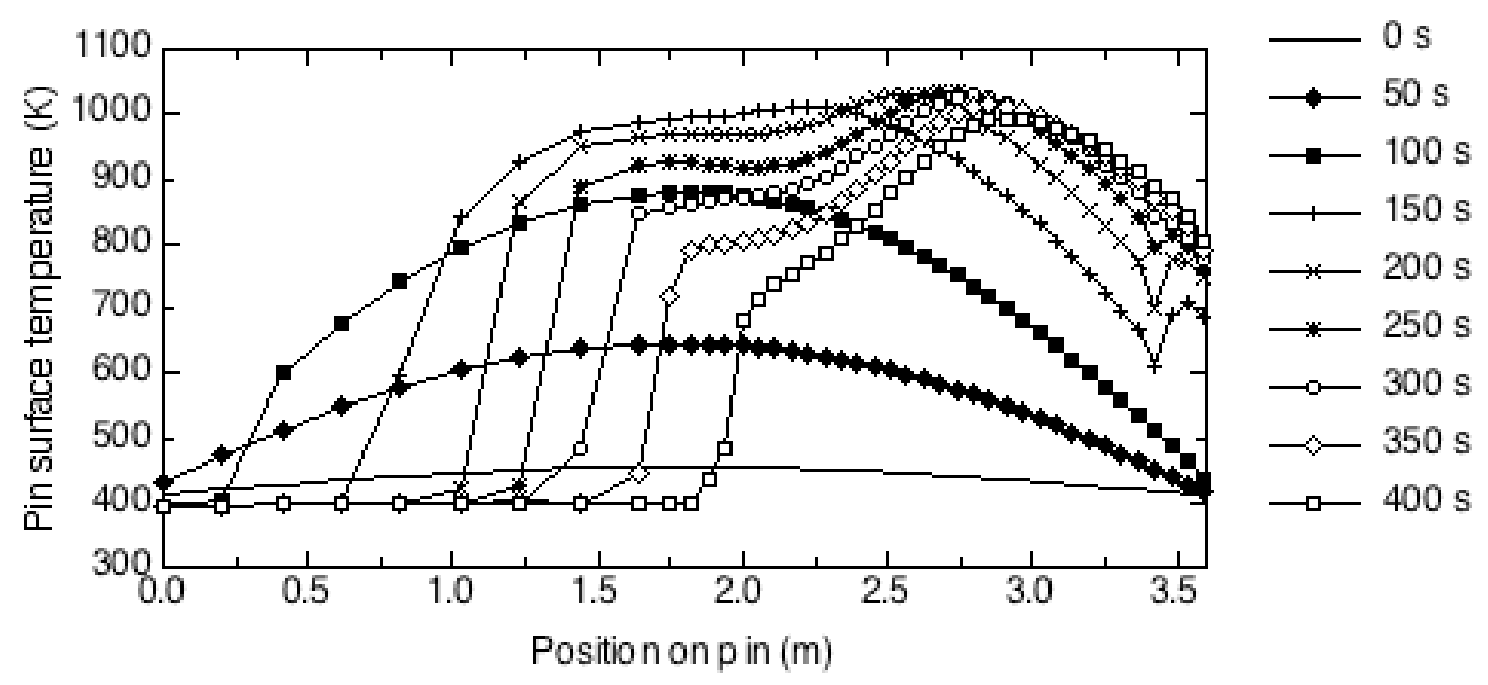

Fig. 4. The course of test SP2, showing the generation of the initial co-sinusoidal temperature distribution, which is then progressively quenched from below as the re-flood water arrives The flattening of the curves between $200 \mathrm{sec}$ and $350 \mathrm{sec}$ should be also noted. This is due to the increase of gap dimensions during ballooning, and thus increased thermal resistance between pellet and cladding. This leads to a reduction of the clad temperature (the 'lift-off' effect).

A further example of the lift-off effect is shown in Fig. 5, where the clad temperature of the ballooned rod as in Test SP1 is plotted. Two plots are shown: one of the temperature as computed by RELAP, and one as by MABEL. The MABEL one (and the one used in this work) takes account of the lifting of the clad from the pellet surface. During the first part of the transient, when the two rods have negligible shape difference, the clad temperatures are identical, being under the same thermal-hydraulic conditions. As the rod shapes become noticeably different, the two temperature profiles diverge, leading to differences of up to 100 degrees. 


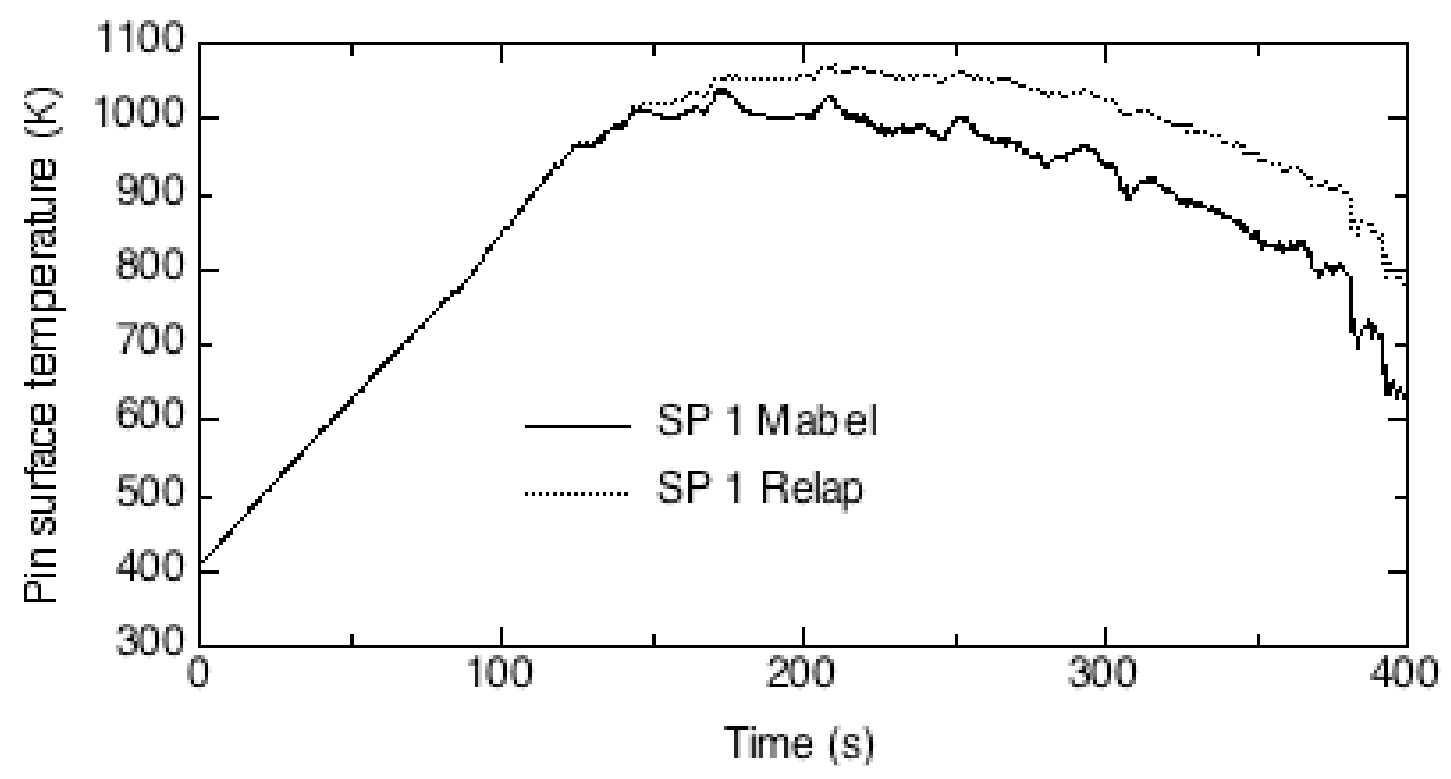

Fig. 5 . Clad temperature history at location $\sim 2.7 \mathrm{~m}$ for test SP1, as computed by MABEL and RELAP respectively.

\subsection{Two pin tests; same pressure}

In test TP1 are analyses of two separate pins, with two instances of MABEL coupled to the RELAP run. There is both-way linkage, here between two identical pins, and the same behaviour is thus expected of each of them. Indeed, observed behaviour is very similar to the (linked) SP2 case, as would be expected.

Test TP2 uses an initial fill pressure some 10\% lower, but is otherwise identical. Results for TP1 and TP2 are shown in Fig. 6, where the reduced swelling caused by this lower gas pressure is plain. The different gas pressure also influences the location where the maximum strain is reached; a higher gas pressure results in an increased ballooning strain, which enhances the local cooling and slightly shifts the swelling peak axially upwards. 


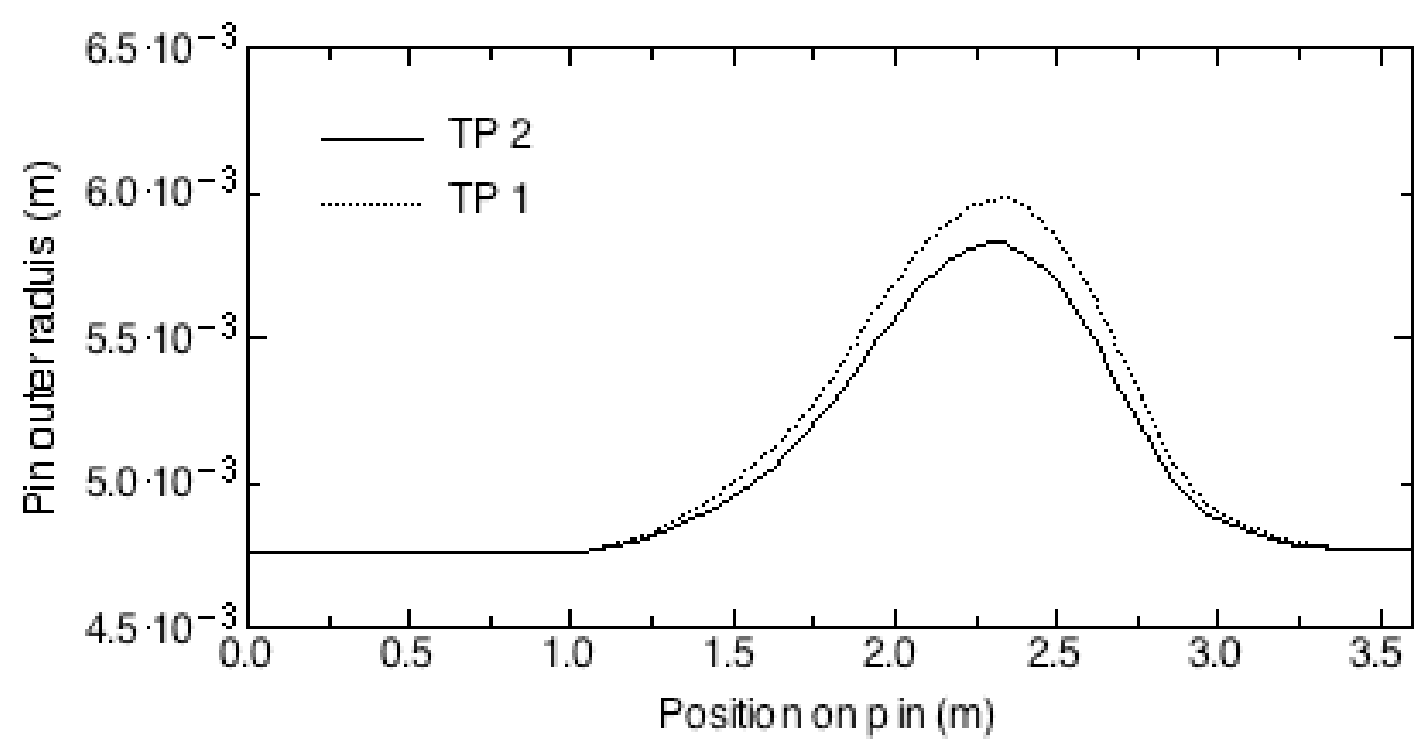

Fig. 6. The ballooning profile for tests TP1 and 2; TP2 has a lower fill pressure (4.07 MPa) than TP1 (4.5 MPa)

The channel flow area in Test TP1, at an axial location of about 2.5 metres, is presented in Fig. 7, and the pin internal pressure in Fig. 8. From these figures can be observed the development of ballooning during the transient.

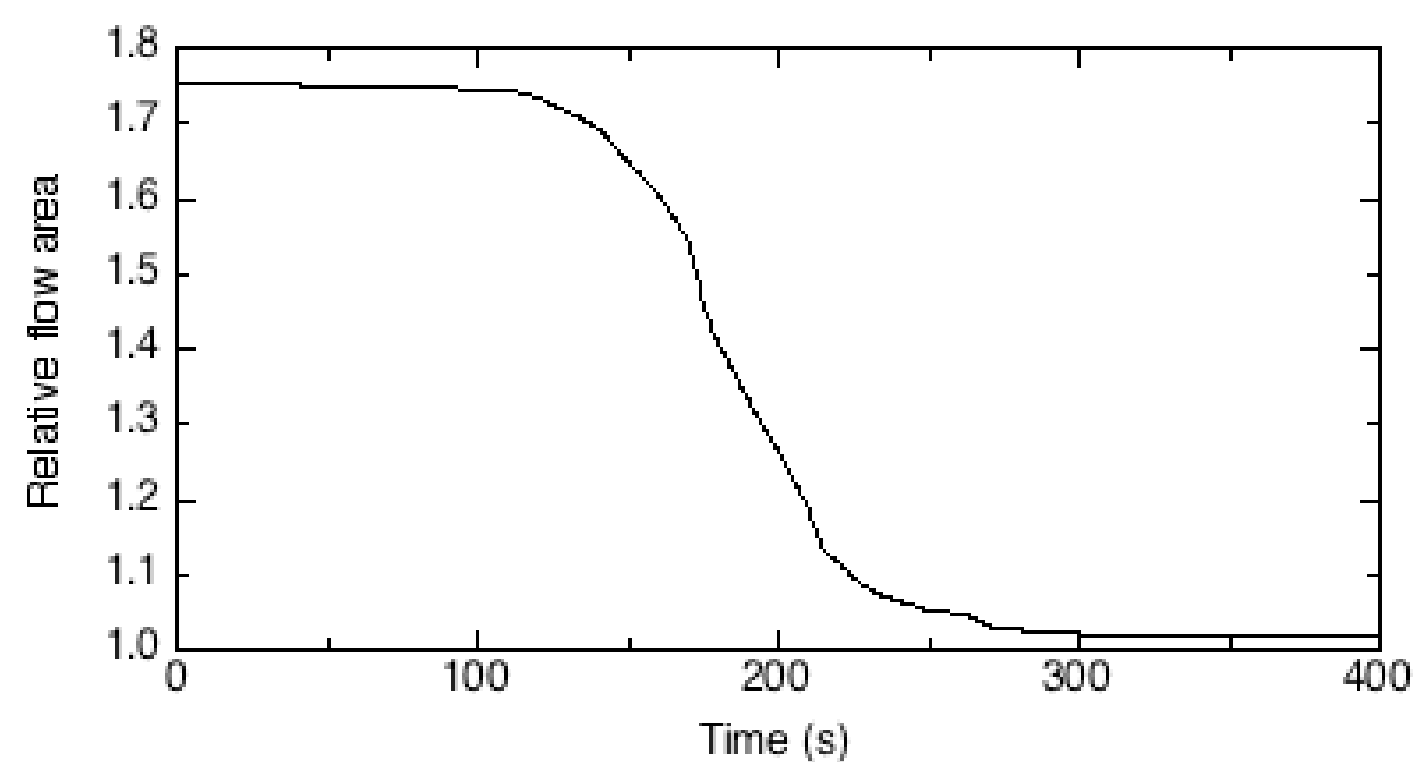

Fig. 7. Test TP1: Relative flow area reduction with time at node 25 (2452-2509 mm)

The rods start to swell soon after 100 seconds, when the internal gas pressure, the driving force for ballooning, reaches its maximum value. The slope of the curve indicates that the swelling is quite rapid between 150 and 210 seconds. Then, the ballooning progressively 
slows down until it stops at about 300 seconds as the increase of the internal volume reduces the gas pressure till a new equilibrium in the system is reached.

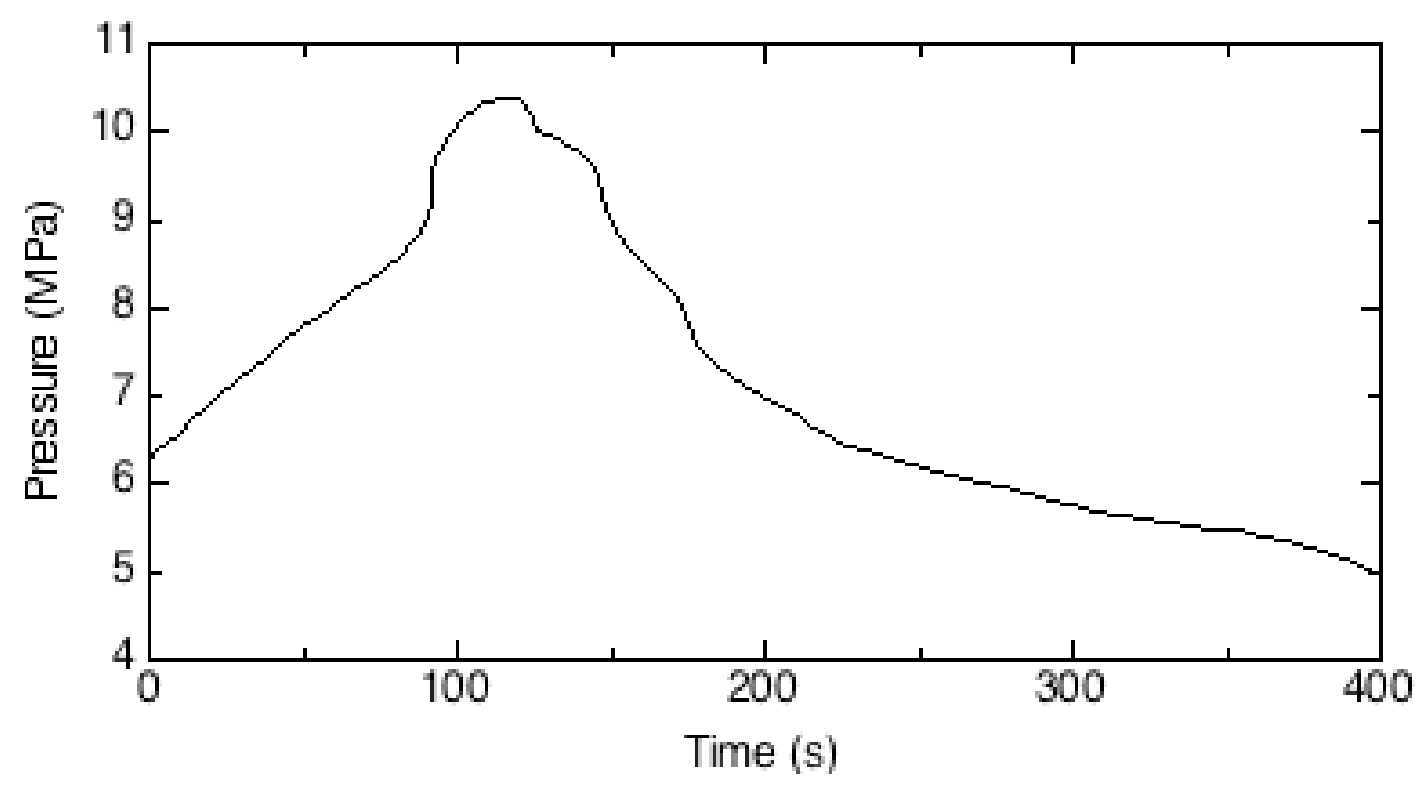

Fig. 8. Test TP1: Pin1 Internal Pressure

\subsection{Two pin tests; pin pressures differ}

Test TP3 involves two pins that have different fill pressures; 4.5 and $4.06 \mathrm{MPa}$, the pressures used in both pins in Tests TP1 and TP2 respectively.

The ballooning of each pin in TP3 is significantly different from its same-pressure counterpart in TP1 or TP2, demonstrating clearly the significant effect that flow diversion can have.

Fig. 9 shows the ballooned profile of the (both $4.5 \mathrm{MPa}$ ) pins of TP1, and of the $4.5 \mathrm{MPa}$ pin of test TP3. Ballooning is significantly greater in the TP3 case. This is because the small ballooning of the second pin of TP3 allows relatively ready diversion of the coolant flow. 


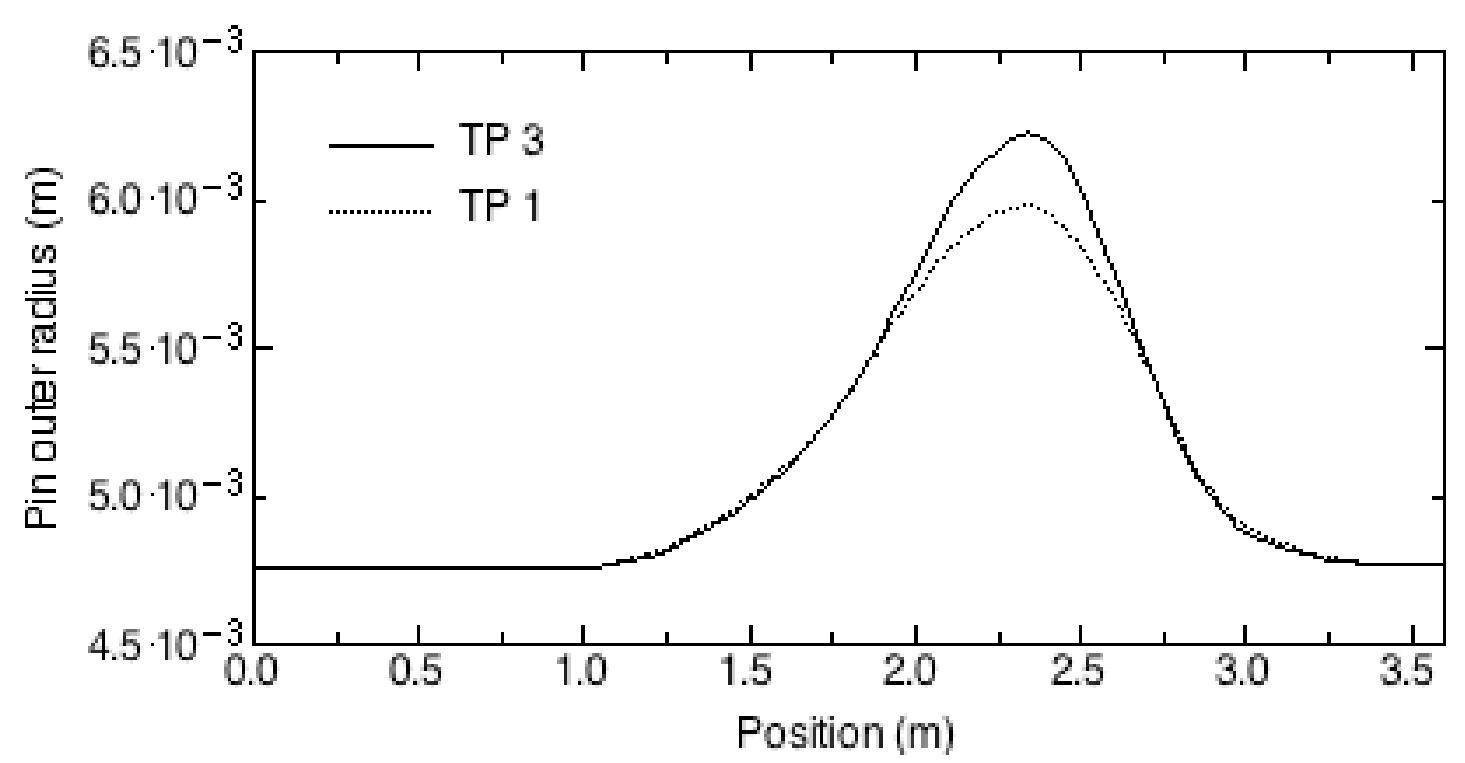

Fig. 9. The ballooned radius (m) of the $4.5 \mathrm{MPa}$ pins of TP1 and the $4.5 \mathrm{MPa}$ TP3.

In Test TP3, the two rods are identical except for the initial gas pressure, equal to $4.5 \mathrm{MPa}$ for Pin 1 as in Test TP1 and equal to $4.07 \mathrm{MPa}$ for Pin 2 as in Test TP2. The final ballooning profile shows that Pin 1 swells more than in case TP1 (Fig. 9), while Pin 2 swells less than in case TP2 (Fig. 10). This different behaviour is ascribed to the flow diversion between the two rods.

Similarly, Fig. 10 shows the ballooned profile of the (both $4.07 \mathrm{MPa}$ ) pins of TP2, and of the 4.07 MPa pin of test TP3. Ballooning is significantly less in the TP3 case. This is because the greater ballooning of the other, 4.5 MPa pin of TP3 causes greater (faster) coolant flow over the 4.07 MPa pin.

Note that the difference in response of the two pins is made up of two factors:

-Higher pressured pins balloon more in their own right, as evidenced by the results of tests TP1 and TP2.

-When a high pressure pin neighbours a low pressure one an additional difference in response is caused by the flow diversion. 


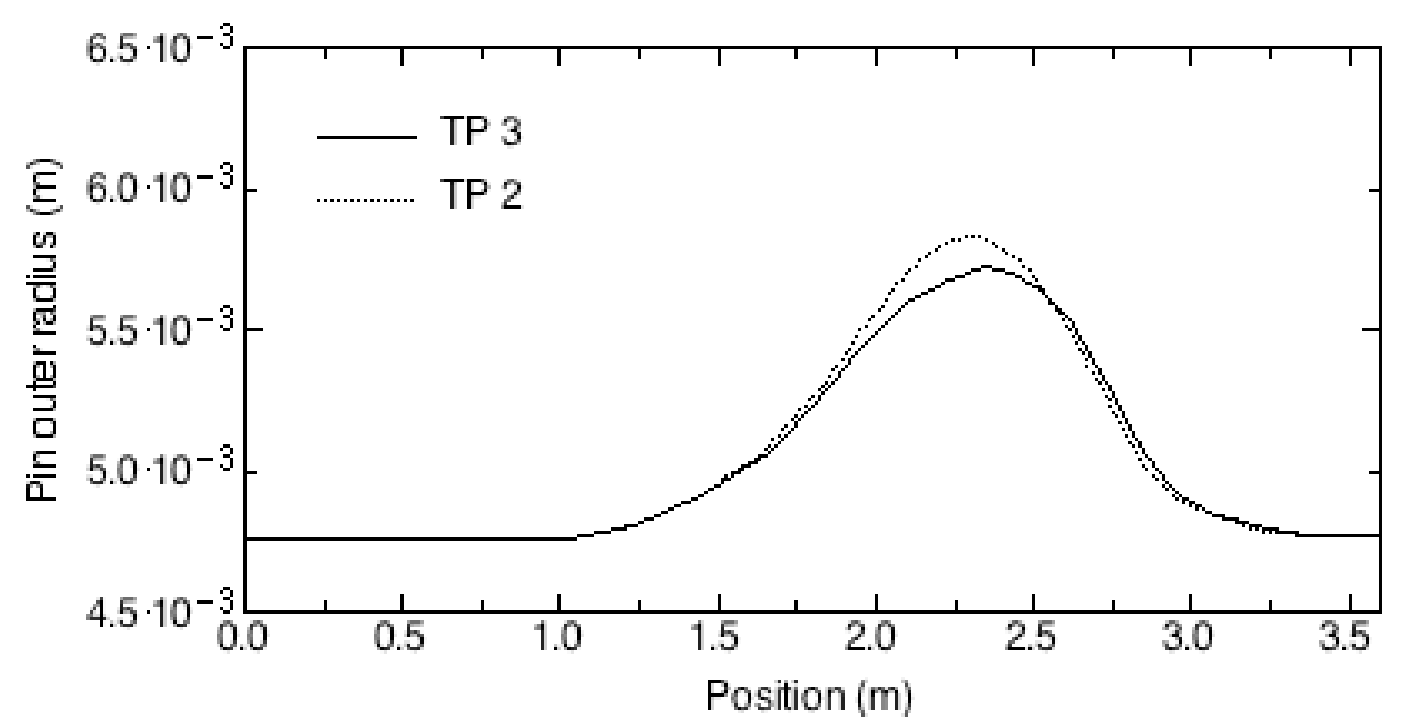

Fig. 10. The ballooned radius (m) of the $4.07 \mathrm{MPa}$ pins of TP2 (solid curve) and the $4.07 \mathrm{MPa}$ TP3 (dashed).

\subsection{Two-pin Tests with grids}

The influence of grids on the fuel rod behaviour in the re-flood phase and, in particular, on the rod ballooning axial profile is investigated in the last two tests.

In these tests, the MATARE grid model described above was implemented. Except for the grid model, the tests are identical to Test TP1 and Test TP3, so that a complete comparison is possible.

The pin pressure in Test TPG1, shown in Fig. 11, is significantly higher than in Test TP1 during most of the transient. The increase in the rod internal volume, which causes the drop of pin pressure, is lower in presence of grids. The grids provide a mechanical constraint on the swelling of the cladding. 


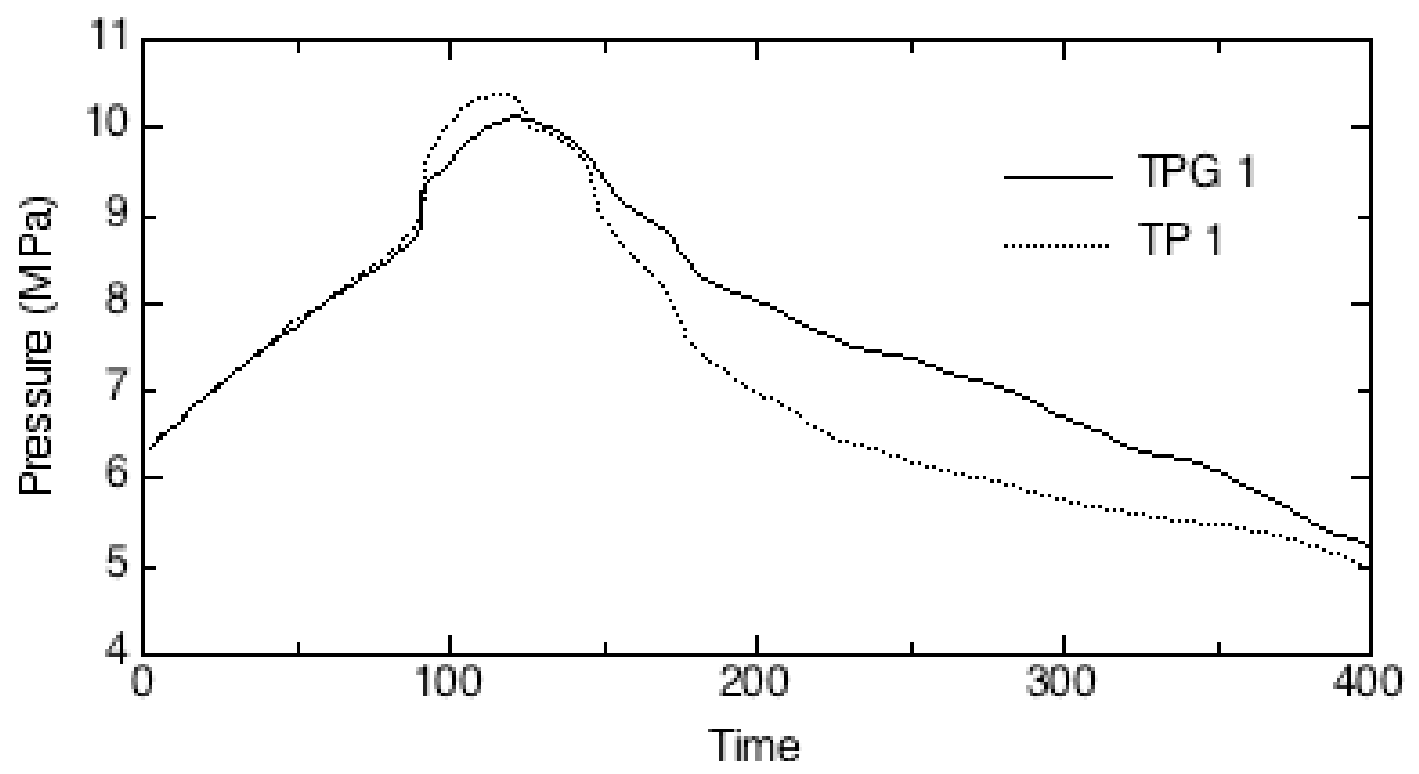

Fig. 11. Pin pressure in Test TP1 (solid) and Test TPG1 (dashed)

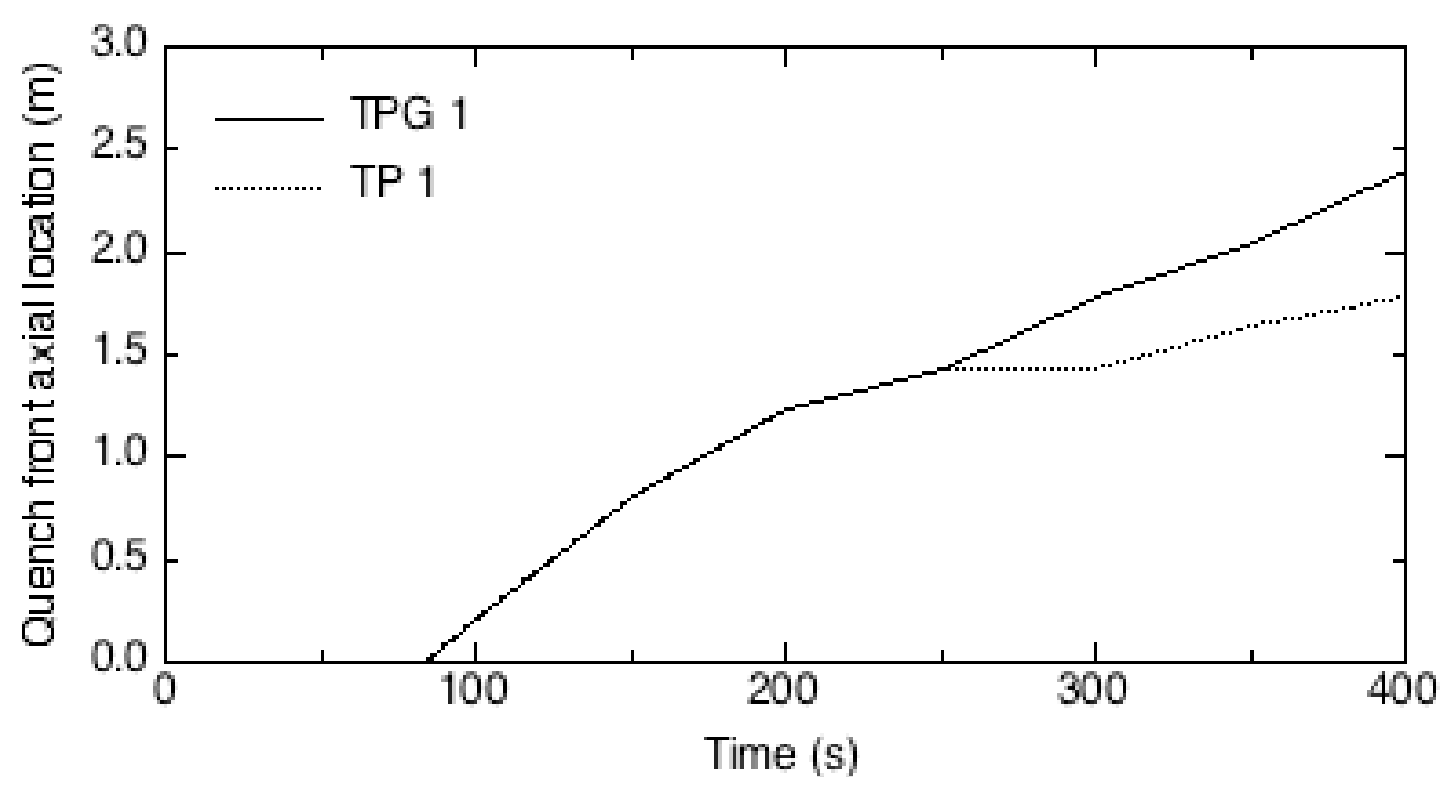

Fig. 12. Quench front axial position in TP1 (solid) and Test TPG1 (dashed)

However, as seen in Fig. 12 the grids affect the advance of the quench front (the location of abrupt transition from film to nucleate boiling). The enhanced heat transfer due to the presence of grids improves the cooling of the cladding, reducing its temperature and leading to more rapid progression of the quench front up the channel. 


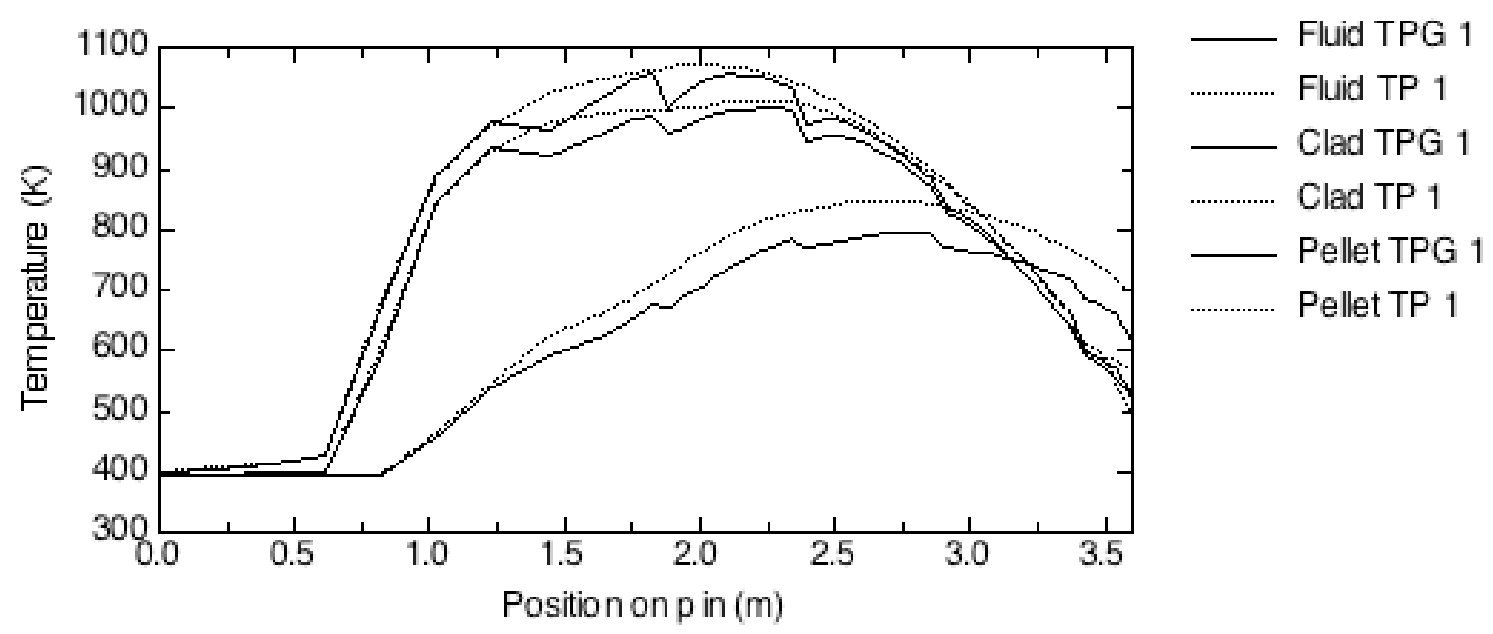

Fig. 13. Pellet, Cladding and Fluid temperature profile (K) over rod length at 200 seconds. TP1 (dashed) and Test TPG1 (solid). Pairs of lines show pellet surface, clad and coolant temperatures for each of the Grid and No-Grid cases.

Moreover, the heat transfer coefficient enhancement, induced by the grids, produces a less severe thermal transient for the rod. As shown in Fig. 13, the pellet, cladding and fluid temperatures are higher in the test without grids. The temperature drops generated across the grids are also apparent.

As a result of the better thermal-hydraulics conditions and the mechanical restraint provided by the grids, the strain over the whole length is reduced, and along with this the maximum peak strain also slightly decreases. Fig. 14 shows the typical carrot-shape of ballooned rod in presence of grids.

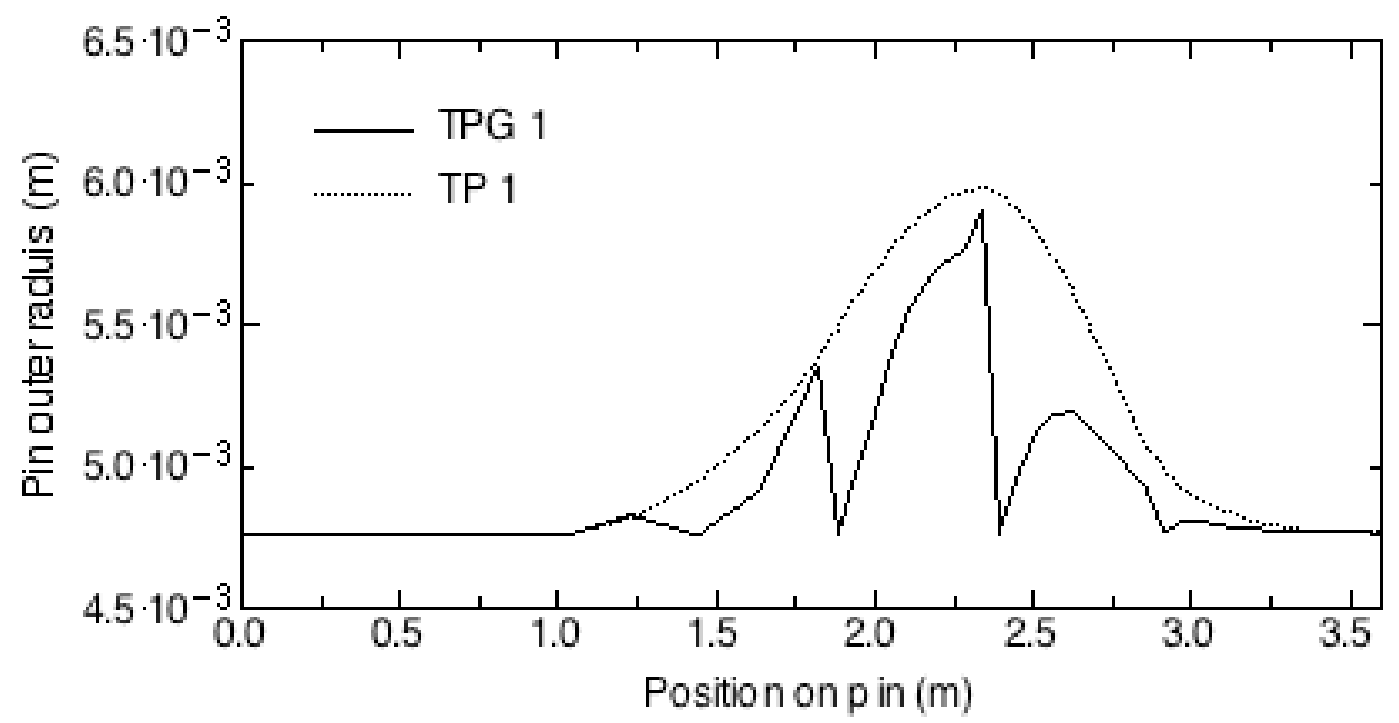

Fig. 14. Comparison of pin radius in tests TP1 and TPG1 
In Test TPG2, the effects of flow diversion, although attenuated by the grids, are still recognisable (Fig. 15).

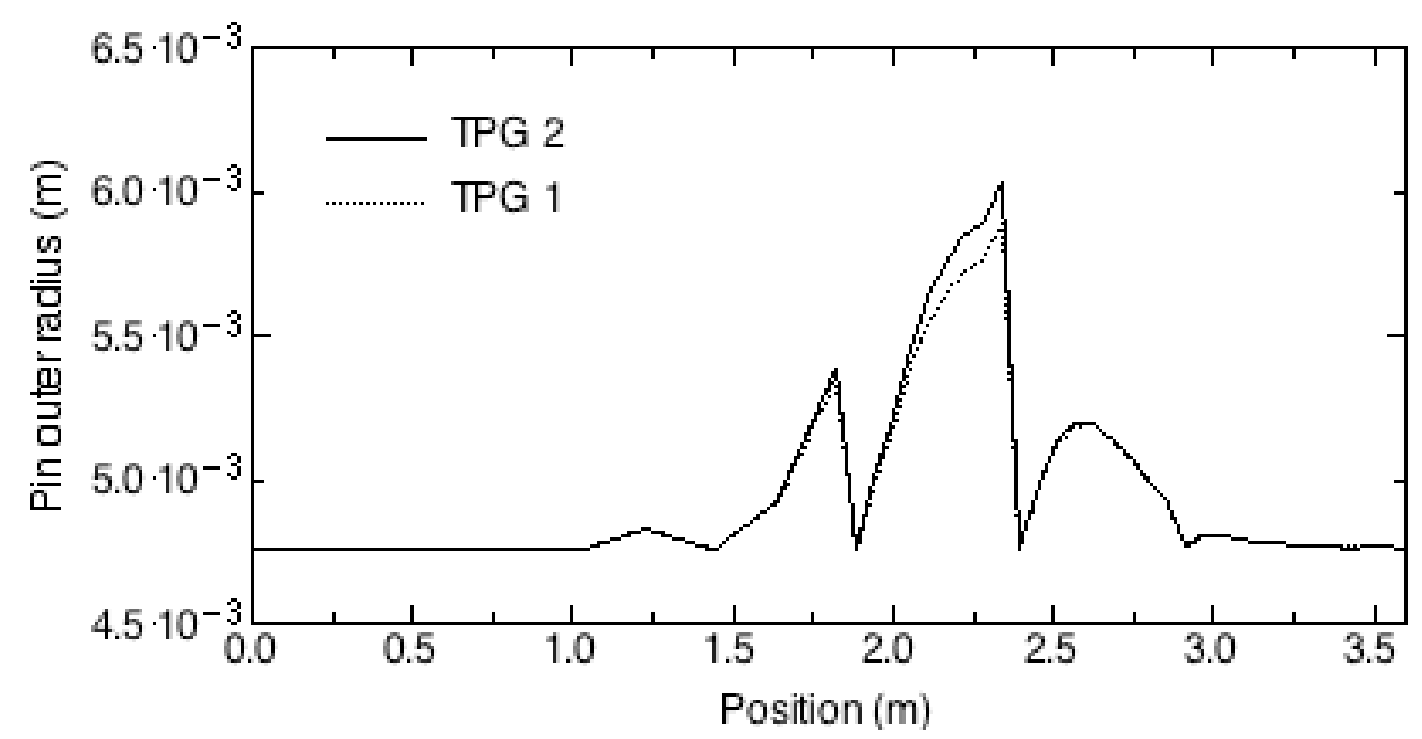

Fig. 15. Variation of pin radius along pin for test TPG1 and TPG2

\section{CONCLUSIONS}

From a practical, model-development point of view, the applications above have demonstrated that the coupling of the RELAP and MABEL codes has been successfully achieved. Stable performance is obtained, with dynamic multi-way linkage and data transfer between MABEL and ReLAP, ReLAP and MABEL, and MABEL and MABEL.

The calculations performed have established that differences between pin parameters result in significant differences in predicted pin behaviour. This is an important encouragement to the more realistic, less conservative modelling of post-LOCA behaviour with incorporation of inter-pin heterogeneity.

Further, the calculations using this coupled model clearly show the potential importance of dynamic feedback mechanisms, with pin deformation clearly influencing thermal-hydraulic behaviour, in turn influencing further mechanical response. 
Future work using this model will address, inter alia, the modelling of multi-pin ballooning experiments, and the modelling of representative sections of full PWR cores undergoing reflood, incorporating both heterogeneity and thermal-hydraulic and mechanical coupling.

\section{ACKNOWLEDGEMENTS}

It is a great pleasure to acknowledge the contribution to this work of Dr J R Jones, of British Energy, and Dr M El-Shanawany (IAEA). We are indebted to them both for many helpful discussions and much valuable advice.

\section{REFERENCES}

Adams, J. E., and Clare, A. J. (1984). "Droplet Break-up and Entrainment at PWR Spacer Grids." Proc. of the First Int. Workshop on Fundamental Aspects of Post-Dryout Heat Transfer, Salt Lake Ciyy, Utah. NUREG/CP-0060, pp. 590-613.

Borgwaldt, H. \& Gulden, W. (1982). SSYST, A Code-system for Analysing Transient LWR Fuel Rod Behaviour under Off-normal Conditions. Water Reactor Fuel Element Performance Computer Modelling, Applied Science Publishers, pp. 663-685.

Bowring, R. H. (1982a). MABEL-2: A code to analyse cladding deformation in a loss-of-coolant accident. Part 1: General Description, Reactor Systems Analysis Division, AEE, Winfrith: Dorchester.

Bowring, R. H. (1982b). MABEL-2: A code to analyse cladding deformation in a loss-of-coolant accident. Part 3: User Notes, Reactor Systems Analysis Division, AEE, Winfrith: Dorchester.

Chapman, R. H. (1978). Multi-rod burst test program: Progress Report. ORNL/NUREG/TM-200.

Donaldson, A. T., Healey, T., and Horwood, A. L. (1985). "Biaxial creep deformation of Zircaloy- PWR fuel cladding in the alpha, (alpha+beta) and beta phase temperature ranges." Water Reactor Fuel Element Performance Computer Modelling, Applied Science Publishers, pp.81-95.

Donaldson, A. T., Horwood, A. L., \& Healey, T. (1983). Pre-test Prediction and Post-test Analysis of PWR Fuel Rod Ballooning in the MT-3 In-pile LOCA Simulation Experiment in the NRU Reactor. Water Reactor Fuel Element Performance Computer Modelling, Applied Science Publishers, pp. 367-385.

Gibson, I. H., Coddington, P., Healey, T., \& Mann, C. A. (1982). The UK MT-3 Ballooning Test in the Battelle NRU Loop. UKAEA Winfrith, AEEW-R 1506.

Healey, T. \& Board, S. (1982). CEGB Proof of Evidence on Fuel Clad Ballooning. Central Electricity Generating Board, CEGB P37.

Ihle, P. \& Rust, K. (1984). FEBA - Flooding Experiments with Blocked Arrays Evaluation Report KfK 3657

Jowitt, D., Cooper, C. A., \& Pearson, K. G. (1984). The THETIS 80\% blocked cluster experiment. UKAEA Winfrith, AEEW-R 1767. 
Karwat, H. (1984). Behaviour of a fuel bundle simulator during a specified heat-up and flooding period (REBEKA Experiment) Lehrstuhl für Reaktordynamik und Reaktorsicherheit Technische Universität München.

Loftus, M. J. (1982). PWR FLECHT-SEASET, 21-Rod Bundle Flow Blockage Task, Data and Analysis Report. NUREG/CR-2444.

Page R. (1999). Description of the TALINK (Rev 1.4) code for the linkage of codes executing in parallel. National Nuclear Corporation Limited.

Pearson, K. G., Denham, M. K., \& Jowitt, D. (1989). ACHILLES Unballooned Cluster Experiments Part1: Description of the ACHILLES Rig, Test Section and Experimental Procedures. UKAEA Winfrith, AEEW-R 2336.

Ransom, W. H. e. a. (1997a). RELAP5/MOD3 Code manual. Volume I: Code Structure, System Models and Solution Methods, NUREG/CR-5535/Vol-I, INEL.

Ransom, W. H. e. a. (1997b). RELAP5/MOD3 Code manual. Volume II: Appendix A Input Requirements, NUREG/CR-5535/Vol-II App.A, INEL.

Yao, S. C., Hochreiter, L. E., and Leech, W. J. (1982). "Heat-Transfer Augmentation in Rod Bundles Near Grid Spacers." Journal of Heat Transfer (104), 76-81. 